\title{
Analysis on difference of commercial rent in allocated land and transferred land in Kunming
}

\author{
Lu Lei ${ }^{1}$, Liu Xiaowei ${ }^{2 *}$, Deng Mingxiang ${ }^{3}$ \\ 1,3. School of Urban and Environment, Yunnan University of Finance and Economics, Kunming, China \\ 2. Yunnan Land Resources Planning and Design Research Institute, Kunming, China \\ 1.54441029@qq.com;2.1eilu812@outlook.com;3.dmx221@163.com
}

\begin{abstract}
Rental shops on allocated lands have always lacked corresponding management measures and trading rules. To provide basis for the formulation of taxation policies for rental shops on allocated lands, this paper investigated the rental shops in the five districts, commercial benchmark land price level 1 to 8 of Kunming on assigned and allocated lands, and carried out the variance hypothesis test on the whole, the districts and the commercial levels. The conclusions are as follows: (1) There are many state-owned enterprises and institutions in the Second Ring Road of Kunming City, mostly are allocated lands; there are many newly developed lands outside the Second Ring Road, mostly are assigned lands. (2) There was no significant difference in the rental shops on assigned and allocated lands in Kunming, and the local differences were significant. (3) The calculation of the income of allocated land shops can refer to the assigned land shops, with a focus on the urban center area and the peripheral areas, and the tax standards can be appropriately lowered in the two areas. Through tax policy, the rent of urban shops should be balanced as far as possible.
\end{abstract}

Keywords—assigned land, allocated land, rental shops, Kunming city

In recent years, the phenomenon of allocated lands for rent in China has become more common. In particular, the housing rental market on allocated lands has become more active. The number of transactions, the wide range of transactions and the high price of transactions have caused widespread public concern. In fact, the transaction of the rental shops market has always been more active. The price of the rental is closely related to the location and price of the land. At present, the types of urban land use rights in China can be divided into assigned land and allocated land. The assigned land users have paid the land grant fee, and the rents of the shop are owned by the lessor. The allocated land is the government's use of land use rights to land users for free. All incomes are owned by the lenders, causing the loss of state revenue. It is necessary to investigate and analyze the differences of rental shops on assigned and allocated land.

At present, the research on rental shops mainly includes the determinants (Nie and Jia 2009, 2010) and pricing method (Yang and Guo 2014), and the comparative analysis of rental shops on assigned and allocated lands has not been involved. Based on the questionnaires survey of rental shops of different commercial levels and different districts in Kunming, this paper analyzed the differences of unit price of rental shops between assigned lands and allocated lands.

\section{SURVEY DATA ANALYSIS}

The scope of this survey includes street shops in

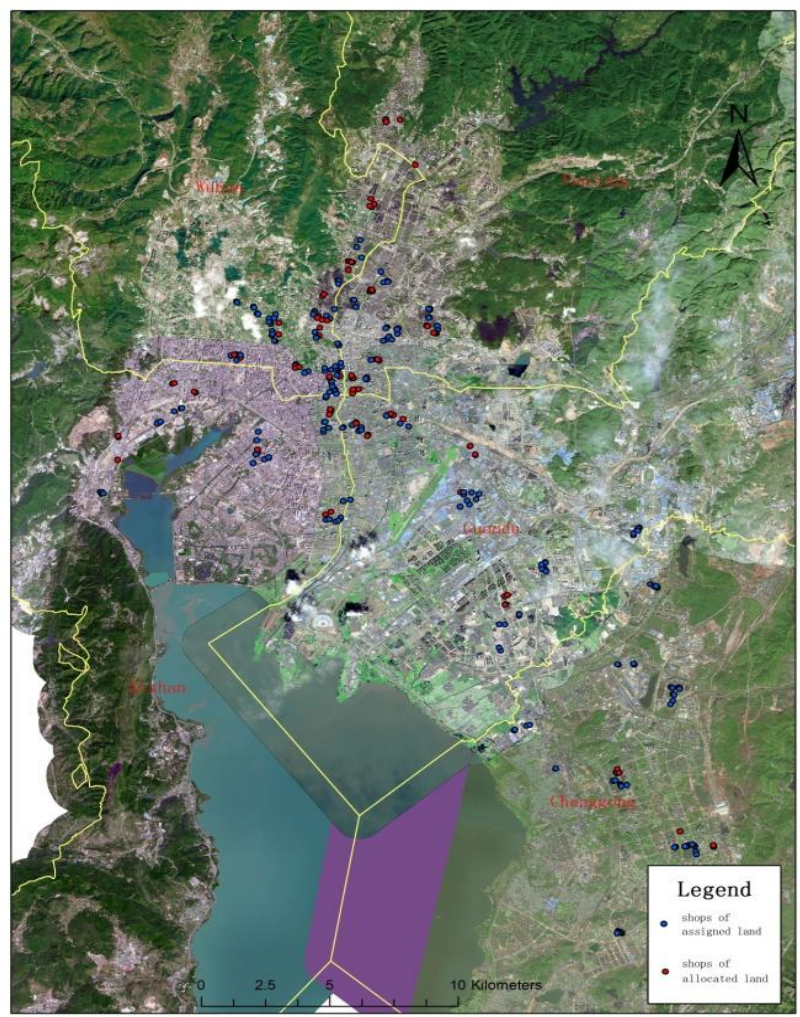

Figure 1 Distribution of surveyed points in Kunming

commercial benchmark land prices ranging from level 1 to 8 in Wuhua, Panlong, Guandu, Xishan and Chenggong district of Kunming. There are more assigned lands than allocated lands in Kunming. The allocated lands are mainly located inside the Second Ring Road. Most newly developed lands outside the Second Ring Road are mainly on assigned lands.

The investigation time was November 2017. The questionnaire content mainly included the location of shops, name, annual rent, tax, area, use, etc. A total of 344 shops were surveyed. 117 shops are on allocated lands and 227shops are on assigned lands.

Survey respondents were small and medium sized shops by street-side. The annual rental of shops were between 2000 and 500,000 yuan, and the area of shops was between 2 and 1300 square meters. The use of shops is mainly clothing, restaurants, department stores, and building materials.

From the results of the survey, some shops gave the renters or intermediary company payment for transfer fees, agency fees, and deposits. In the operation of shops, utilities, property management fees, health expenses, urban management fees, etc. were not included in the rental shops. Most shops were tax-free. There were also some shops that were required to pay a small amount of tax. The taxes were 
included in the rent, and were not charged separately. The amounts to be paid separately were low, local tax, national tax, and business taxes were within 1,000 yuan per month. No additional taxes and fees have been charged, which is consistent with the operation modes of shops in assigned lands.

\section{ANALYSIS OF THE DIFFERENCES OF RENTAL SHOPS IN}

\section{KUNMING CITY}

In order to make the data comparable, the rent unit price was analyzed, that is, the annual rental shops was divided by the floor area of the shop. Analyze whether there are significant differences between the 227 unit prices of rental shops on assigned lands and 117 rental shops on allocated

Table 1 Descriptive Statistics of Shop rent of Kunming in 2017

\begin{tabular}{|c|c|c|c|c|c|c|}
\hline \multirow{2}{*}{ Types } & \multirow{2}{*}{$\mathrm{N}$} & \multicolumn{5}{|c|}{ Rent (yuan per square meter) } \\
\cline { 3 - 7 } & & Mean & Median & Std. Deviations & Minimum & Maximum \\
\hline Assign & 227 & 1718.87 & 1162.16 & 1732.30 & 38.19 & 12500.00 \\
\hline Allocation & 117 & 1775.28 & 1333.33 & 1334.08 & 263.16 & 6538.46 \\
\hline
\end{tabular}

Tab.2 ANOVA

\begin{tabular}{|c|c|c|c|c|c|}
\hline & Sum of Squares & df & Mean Square & F & Sig. \\
\hline Between Groups & 245626.212 & 1 & 245626.212 & 0.095 & 0.758 \\
\hline Within Groups & 884643575.0 & 342 & 2586677.120 & & \\
\hline Total & 884889201.2 & 343 & & & \\
\hline
\end{tabular}

lands. Variance hypothesis test was used.

The average unit price of rental shops in allocated lands is slightly higher than shops in assigned land. From the standard deviation, the minimum value, and the maximum value, it can be seen that there is a greater degree of dispersion in the unit price of the rental shops on assigned lands.

Suppose there is no significant difference in the unit price of rental shops on allocated and assigned lands. From the homogeneity test of variance, the significance is $0.335>0.05$. The homogeneity of variance is equal, and the analysis of variance can be carried out. According to the results of analysis of variance, the significance is $0.758>0.05$. It can be concluded that there is no significant difference in the unit price of rental shops on allocated and assigned lands.

Allocated land is allocated by the country to units or individuals for free, but the rent is collected by land users, causing the loss of state revenue.

\section{COMPARISON OF DIFFERENCES BETWEEN REGIONS}

The average unit prices of rental shops in Wuhua, Panlong, Xishan, Guandu and Chenggong districts are 2027, $1725,1738,1656$, and 1356 yuan per square meter respectively in Kunming.

The rent is affected by the economic development. Except for Guandu District, the unit price of rental shops is consistent with the distribution of GDP in 2016 in other four districts of Kunming. Guandu District has developed rapidly in recent years. The GDP from 2011 to 2015 was lower than Wuhua District, but the gap has narrowed continuously. In 2016, it exceeded Wuhua District. Guandu District has continuously increased investment in fixed assets, and increased investment in education. GDP of Guandu District has grown significantly. Since the commercial location is not as good as Wuhua District, the rent in Guandu District is lower than Wuhua District, which is not much different from Panlong District and Xishan District.

From the difference between the unit prices of rental shops in allocated and assigned lands at all districts:

The unit price of rental shops on allocated and assigned lands in Wuhua District is homogeneity of the variance, and there is no significant difference. The built-up areas in Wuhua District are concentrated and cover some areas of commercial benchmark land from commercial level 1 to 8 and occupy a larger area at the first and second levels. The overall rent of shops is higher. Shops are mainly on assigned lands at the first commercial level, and the unit price of rents is widely dispersed. There is little difference in the unit price of rent on the allocated land.

The unit price of rental shops on allocated and assigned lands in Panlong District is homogeneity of the variance, and there is no significant difference. The unit price of Panlong District is lower than Wuhua District, and the commercial levels are from fist to eighth levels. The levels of first and second are relatively small. The allocated and assigned lands are evenly distributed, and the average, minimum and maximum prices of shops are not much different.

The unit price of rental shops on assigned lands is significantly higher than that on allocated lands in Xishan district. The highest unit price of rental shops on allocated lands is only 1,750 yuan per square meter. The commercial levels are from second to eighth levels and the second level is relatively small. The rental shops on located lands is remote in Xishan District, mainly located in the west of Dianchi Lake, where shops mainly located in schools and logistics companies have lower rents. The rental shops on located lands near the central city are also mainly small-scale shops in state-owned enterprises and schools, and less allocated lands near commercial functional areas. Therefore, there are significant differences in the rents for the allocated and assigned lands in Xishan District.

The unit price of rental shops on assigned lands is significantly higher than that on allocated lands in Guandu district. There is a big difference between the minimum and maximum prices of the rental shops on assigned lands. The commercial levels are from third to seventh, and the second level is relatively small. The survey samples of allocated land shops are concentrated in third to fifth levels. There is not much difference in rental shops on allocated and assigned lands in central urban areas, but some of the allocated lands near the outskirts of the city belong to state-owned enterprises, and the unit price of rent is far lower than the unit price of shops on assigned lands.

The unit price of rental shops on allocated lands is significantly higher than that on assigned lands in Chenggong district. The commercial levels are from sixth to eighth.Chenggong District is a newly-developed area in Kunming City. The overall level of land prices and shop rents are relatively low, and the allocation lands is small.The allocated lands are mainly in colleges in the University City, where the population and business districts are proofread, and the unit prices for shops are high.

\section{COMPARISON OF DIFFERENCES BETWEEN COMMERCIAL}

\section{LEVELS}

The commercial benchmark land price level is determined based on the supply and demand conditions of commercial land. Same level is homogeneous. According to the 2014 standard, the commercial benchmark land price in 
Kunming has eight levels, and the average unit prices of shops in these eight levels are compared. The unit prices of rental shops from commercial level 1 to level 8 are respectively $4155,2805,1853,1321,1437,1262,1533$, and 1088 yuan per square meter. On the whole, from the commercial level 1to the commercial level 8, rents are decreasing, and the unit rents of shops from level 1 to leve 4 have decreased significantly. However, the differences from level 4 to 8 are not obvious. The closer the shops are to the commercial centers of Kunming, the greater the increase in rent; the closer to the outskirts of the city, the lower the downward trend in rent.

From the difference between the unit prices of rental shops in allocated and assigned lands at all levels:

The commercial level 8 is basically located in Chenggong District and it is difficult to find survey samples on allocated lands. The analysis of variance is only applied to unit price of shops from the commercial level 1 to level 7 . Research whether there is a significant difference in the rental shops between allocated lands and assigned lands. The unit rents of shops from commercial level 3 to 7 fit the normal distribution, and there is no significant difference in the unit price of assigned and allocated lands.

The unit price of rental shops on assigned lands is significantly higher than that on allocated lands in first and second commercial levels. The proportion of area at the commercial level 1 to commercial benchmark land area is $0.43 \%$ and level 2 is $1.66 \%$. The number of survey samples is small, and the data fluctuation is large. The highest price is at the center of the first level, which is mainly assigned lands. The allocated lands are located near the outer area at the commercial level 1 , and the price has dropped significantly. Commercial function areas at level 2are concentrated, and the unit price of shops on assigned lands is obviously higher than that on the allocated land.

\section{CONCLUSION AND SUGGESTION}

Through the investigation and analysis of the rental shops on assigned and allocated land in Kunming, the following conclusions and recommendations are drawn:

(1) There are many old state-owned enterprises and institutions in the Second Ring Road mainly on allocated lands; and there are more newly developed lands outside the Second Ring Road mainly on assigned lands in Kunming.

(2)There is no significant difference of rental shops on the assigned and allocated lands in Kunming, and the local differences were significant. 1) The rent growth is fast in the central area, and the rent difference in suburban is small. 2) The rental shops growth is faster from commercial level 1 to level 4. The rental shops on assigned lands are greatly affected by market and are often higher than that on the allocated lands at level 1 and 2. 3) Some old state-owned enterprises are located in the outskirts of Kunming, and there are no commercial areas around. The shops mainly serve nearby residents and factory workers. The rents are lower than the shops in the surrounding residential areas.

(3) The rent of the shop is charged by the lessor, and the standard of taxes and fees on allocated land is consistent with the assigned land. The tax of the small and medium-sized shops is mostly included in the rent. Although the range of rent unit price on assigned land is greater than that on allocated land, there is no significant difference as a whole. The tax revenues for rented shops on allocated lands can be calculated by reference to the proceeds from assigned lands. Focusing on the center area and the peripheral areas, the tax standards can be appropriately lowered, and the rents of shops should be balanced as much as possible through taxation.

\section{ACKNOWLEDGMENTS}

This work was supported by the National Natural Science Foundation of China Projects (NSFC) number 41562017.

\section{REFERENCES}

[1] Nie C. and Jia S.H. (2009). An Empirical Study on the Micro Determinants of Rental Shops of Shopping Mall Based on the Characteristic Price Model [J]. Finance and Trade Economy, 4:113-117. (in Chinese)

[2] Nie C. and Jia S.H. (2010). An Empirical Study on the Determinants and Tenant Composition of Non-Main Stores in Shopping Centers [J]. Finance and Trade Economy, 8:103-108. (in Chinese).

[3] Yang Q.F. and Guo M. (2014). Research on the Optimization of Rent Pricing Method of Urban Metro Shops [J]. Railway Transport and Economy, 36(10):81-86. (in Chinese). 